\title{
O CUIDADO E O CARECER \\ (A co-originariedade entre os existenciais de Ser e tempo)
}

Flavio Costa Balod*

SÍNTESE - Segundo Ser e tempo, o cuidado, como ser do ser-aí, é definível pela expressão complexa "ser-já-precedentemente-a-si-em (o mundo) como ser-junto-a (ente intramundano que vem ao en-contro)", a qual é apresentada deste modo no Parágrafo 41, que trata de "O ser do ser-aí como cuidado". Nesta expressão, pretende Heidegger indicar cada um dos existenciais (disposição, compreender, fala, assim como também decair e mundo), e condição da correta compreensão do sentido desta estrutura é o entendimento de que há co-originariedade (Gleichursprünglichkeit) entre eles, isto é, de que a abertura de mundo só ocorre como resultado dos existenciais conjuntamente. Sem pretender contestar tal co-originariedade entre os existenciais no que diz respeito à abertura de mundo (e, portanto, do ser), pretendemos apenas chamar a atenção para o fato de que tal condição da abertura não implica necessariamente que os caracteres do ser do ser-aí tenham que ser entendidos como simultaneamente genéticos na abertura, mas apenas da abertura, e que o ser do ser-aí como cuidado tem seu fundamento originário no carecer. Este último constitui os Em-virtude-de-quê? (Worumwillen) que determinam as disposições, a partir das quais vem a ser as totalidades conformativas (Bewandtnisganzheiten) estabelecidas, como significâncias, no compreender interpretativo, sendo ambos, disposição e compreender, articulados pela fala, com o que tem origem, então, abertura de mundo. Sendo assim, já que o ser do ser-aí é disposição compreensiva e falante no mundo, percebe-se por que se afirma aqui que o fundamento do cuidado como ser do ser-
ABSTRACT - According to Being and Time, care, as the being of Dasein, is definable by the complex expression "ahead-of-itself-Being-already-in-(the world) as Being-alongside (entities encountered within-the-world)", which is presented this way in Paragraph 41, that approaches "Dasein's Being as Care". Through this expression, Heidegger intends to point out each one of the existentialia (state-ofmind, understanding, discourse, as well as falling and world), and as condition to the correct understanding of the meaning of this structure is the understanding of the fact that there is equiprimordiality (Gleichursprünglichkeit) among them, that is, that the world disclosedness only occurs as a result of the existentialia in conjunction. Without intending to contest this equiprimordiality among the existentialia with respect to the disclosedness of world, (and, therefore, of Being) we just intend to call attention to the fact that this condition of the disclosedness does not necessarily mean that the characters of the Being of Dasein have to be understood as simultaneously genetic in the disclosedness, but only for the disclosedness, and that the being of Dasein as care has its original basis in the need. The latter constitutes the for-the-sake-ofwhich (Worumwillen) that determine the state-ofmind, from which the totality of involvements (Bewandtnisganzheiten) are established, as significance, in the interpretative understanding, where both - state-of-mind and understanding - are articulated by discourse, with which there is, therefore, the origin of world disclosedness. This way, as the being of Dasein is a discoursing and understanding state-of-mind in the world, it is possible to realize why it is said here that the basis of care as being of Dasein is the need. However, it

* Doutor em Filosofia pela UFRJ. Professor do Colégio Pedro II (RJ).

\begin{tabular}{|l|l|l|l|l|l|}
\hline VERITAS & Porto Alegre & v. 51 & n. 2 & Junho 2006 & p. 17-27 \\
\hline
\end{tabular}


aí é o carecer. Contudo, só é possível dizer que o ser do ser-aí é o cuidado caso a angústia, disposição que corresponde ao saber da morte como compreender projetivo, se manifeste, própria ou impropriamente.

PALAVRAS-CHAVE - Ser-aí. Disposição. Compreender. Fala. Impessoal. Angústia. Cuidado. is only possible to affirm that the being of beingthere is care if anxiety, the state-of-mind that corresponds to the awareness of death as a projective understanding, manifests itself, either properly or improperly.

KEY WORDS - Dasein. State-of-mind. Understanding. Discourse. Anxiety. Care.

A expressão "ser-já-precedentemente-a-si-em (o mundo) como ser-junto-a (ente intramundano que vem ao encontro)", assim apresentada no Parágrafo 41 de Ser e tempo e repetida à página 327 (Parágrafo 65), pretende definir o cuidado, isto é, o ser do ser-aí. Nesta expressão estão indicados os existenciais, caracteres de ser do seraí que são condição para que haja, para este ente, abertura de mundo e, por conseguinte, abertura de ser: a disposição (Befindlichkeit), o compreender (Verstehen), a fala (Rede) e o decair. Tais existenciais são, nos diz Heidegger, co-originários, em relação à abertura e em nosso trabalho procuramos verificar em que consiste tal co-originariedade entre disposição, compreender e fala. Certas conclusões não expressadas em Ser e tempo serão, veremos, corolário inevitável desta verificação.

\section{I - O mundo}

O que se abre para o ser-aí, este ente privilegiado por meio do qual temos acesso ao sentido do ser, é o mundo. Abre-se como conjunto de totalidades conformativas (Bewandtnisganzheiten) que se estabelecem entre os entes, posto que estes, os entes, aparecem para nós, de início e na maioria das vezes (para usar esta recorrente indicação, por Heidegger, da cotidianidade), como manuseáveis (Zuhandenen): "O modo de ser do utensílio, no qual ele se manifesta a partir de si mesmo, nós o chamamos de manuseabilidade (Zuhandenheit)" (Heidegger 1986, p.69). A conformidade (Bewandtnis) de um ente em relação a outro é estabelecida pelo ser-para de cada ente específico. Neste sentido, o ser-para do martelo é o martelar, o ser-para do martelar é fixação do prego, que pode ser-para esta ou aquela parede (dependendo do material de que é feita), e a fixação na parede é-para manter o quadro pendurado. Esta "corrente" estabelecida do martelo ao quadro pendurado perfaz uma totalidade conformativa. Neste exemplo que citamos, a totalidade tem lugar no tempo; contudo, também no espaço, constroem-se as Bewandtnisganzheiten. Pois o quadro de ferramentas exposto na parede de uma oficina de técnico em eletrônica também compõe uma totalidade, pois todas as ferramentas estão distribuídas e ocupando o lugar que lhes é devido em razão das relações estabelecidas entre elas pelas suas diversas empregabilidades determinadas. No escritório de um tradutor, são os dicionários que ocupam os lugares nas prateleiras mais próximos à sua mesa - à sua mão. Outros livros de consulta estarão imediatamente mais distantes e assim por diante. O escritório é, também ele, uma totalidade conformativa estabelecida espacialmente. 
A conformidade se constitui, segundo Heidegger, como um "deixar ser conforme com algo junto a algo" e esta relação deve ser indicada pelo termo referência (Verweisung). Tal referência, que se expressa quando perguntamos "A que isto é conforme?", é visada todas as vezes em que perguntamos "Para que isto é utilizável?" ou "Em que isto é empregável?". Portanto, para que os entes apareçam para nós (ou, simplesmente, para que sejam entes, isto é, para que tenham ser), é preciso que se inscrevam em totalidades de referência constituídas por meio destes Para quê? e Em quê?. É possível que o seu ser-para nos seja, eventualmente, desconhecido - neste caso, o ente não será, para nós, um manuseável, mas sim algo simplesmente-dado. Mas este caso é excepcional, e quando ocorre já de imediato preocupamo-nos em inscrever este ente em uma totalidade conformativa, de modo a poder responder à pergunta: "- O que é isto?". Contudo, tais totalidades vêm a ser, primariamente, desde um fundamento que não pode ser identificado como referência, como conformidade, pois não se expressa, a rigor, nestas perguntas Para quê? ou Em quê?, mas sim na questão "Em virtude de quê?", na qual nos remetemos ao ser do ser-aí mesmo. Pois, diz Heidegger:

Conformidade é o ser do ente intramundano, para o qual o ente já é de imediato, a cada vez, liberado. Com ele, como ente, tem ele a cada vez uma conformidade. [...] Aquilo Junto a quê? este último tem a conformidade é o Para quê? da serventia, o Em quê? da empregabilidade. Com o Para quê? da serventia pode ele, por sua vez, ter sua conformidade; por exemplo, com este manuseável, que por isto chamamos de martelo, tem ele a conformidade junto ao martelar, com o martelar tem ele sua conformidade junto à fixação, com a fixação tem ele sua conformidade junto à proteção contra 0 mau-tempo; a proteção 'é' em virtude do abrigar-se do ser-aí, isto é, em virtude de uma possibilidade do seu ser. Qual conformidade ele tem com um manuseável, isto já é pré-definido a partir da totalidade conformativa. [...] Mas a totalidade conformativa mesma remonta, em última instância, a um Para quê?, junto ao qual não se dá mais nenhuma conformidade, um Para quê? que não é ele mesmo ente no modo de ser do manuseável em meio ao mundo, senão que ente cujo ser é determinado como ser-nomundo, ente a cuja constituição de ser pertence mundanidade mesma. Este Para quê? primário não é nenhum para-isto como possível Junto a quê? de uma conformidade. O 'Para quê?' primário é um Em virtude de quê?. O 'em-virtude-de', porém, diz respeito sempre ao ser do ser-aí, para o qual se trata essencialmente deste ser mesmo. (Heidegger 1986, p. 84)

E diz respeito, assim interpretamos, como expressão daquilo de que o ser-aí carece. Nesta citação que acabamos de fazer, é a necessidade ou carência de proteção contra o mau-tempo que dá origem à cadeia de conformidades descrita por Heidegger, ficando, por conseguinte, claro que nos em-virtude-de expressam-se as carências do ser-aí. Não obstante, todas as relações que dão lugar às totalidades conformativas são nomeadas por Heidegger como significâncias (Bedeutsamkeiten), inclusive aquelas que têm por base um em-virtude-de. No compreender, como existencial, tais relações são significadas, e isto desde o em-virtude-de mesmo, isto é, desde o ser do ser-aí. Mundo se abre, para o ser-aí, nesta rede de relações de significância, abre-se como totalidade conformativa, como totalidade das totalidades conformativas e portanto é tributário, como já veremos mais detidamente, da ação do compreender. 


\section{II - A disposição}

Todo compreender é disposto, nos diz o filósofo. E isto quer dizer que mundo se abre sempre desde estados de humor. O termo disposição, afirma Heidegger, indica ontologicamente aquilo que onticamente é "o mais conhecido e o mais cotidiano: o humor, o estar humorado". Não obstante esta distinção, o filósofo usa ambos os termos para designar certos estados emocionais, certos modos de "se estar". Chama o temor, por exemplo, de disposição no título do Parágrafo 30. Admitindo-se que disposição, compreender, fala e decair sejam apenas termos genéricos que ganham especificações ônticas nos diversos estados de humor, nos projetos, nas linguagens (entre elas a verbal) e nas diversas lidas impróprias com os entes, admitindo-se isto pouco importa tal distinção. Importa, mais que isto, verificar que na disposição abre-se para o ser-aí sua específica facticidade, isto é, abre-se para ele a situação em que se encontra, em que foi, por assim dizer, lançado. "O conceito de facticidade encerra em si: o ser-no-mundo de um ente , intramundano' de tal modo que este ente possa compreender-se como ligado em seu, envio' com o ser do ente que lhe vem ao encontro dentro de seu próprio mundo" (Heidegger 1986, p. 56). A situação em que se encontra, que não depende do ser-aí dado que o precede (nela é ele lançado), abre-se, contudo, para ele em virtude dos seus estados de humor. Acontece freqüentemente de estarmos junto aos outros, mas a situação constituída pelos entes que nos vem ao encontro, aos quais estamos ligados no "'envio' (...) dentro do próprio mundo", situação que, em princípio seria a mesma para todos, abre-se diferentemente para cada um, dependendo do estado de humor específico de cada um. Uma mesma situação dada (um mesmo envio junto aos entes) pode ser triste ou alegre - dependendo do estado de humor de cada um.

Este abrir a facticidade constitui o primeiro dos três caracteres ontológicos da disposição: "a disposição abre o ser-aí em sua condição de estar lançado e, de início e na maioria das vezes, no modo do desvio que se esquiva" (Heidegger 1986, p. 136). Este "desvio que se esquiva" refere-se ao decair num ser impróprio desde nosso modo próprio de ser. Constitui o que a cotidianidade é normalmente quando, por força da influência dos outros e em razão da nossa fuga do que seria nosso ser próprio, assumimos uma existência imprópria. Interessa observar aqui que na disposição está a raiz, o fundamento do "modo de ser próprio", da propriedade, conclusão a que podemos chegar com base no Parágrafo 29. Pois de que outro modo interpretaríamos o dizer de Heidegger de que "no mais das vezes o ser-aí esquiva-se ôntico-existenciariamente do ser aberto no humor"(Heidegger 1986, p. 135), sendo que "a constituição existencial deste esquivar-se" evidencia-se "no fenômeno do decair" (Heidegger 1986, p. 139)? O ser-aí esquiva-se daquilo que é aberto na disposição, isto é, na disposição própria e esta é básica em relação à impropriedade. Afirma-o o próprio Heidegger quando diz, à página 259 de Ser e tempo, que "impropriedade tem uma possível propriedade como fundamento". 
O segundo dos caracteres ontológicos da disposição consiste em que "a disposição já sempre abriu o ser-no-mundo como totalidade e torna possível antes de mais nada um direcionar-se para..." (Heidegger 1986, p. 137). A disposição dispõe a direção; o percurso, determina-o o compreender interpretativo. Articulando os dois atua a fala e, então, ocorre abertura de mundo. Esta última é gerada, pois, co-originariamente pelos três existenciais, mas toda e qualquer abertura é disposta, ou seja, é possível apenas a partir da disposição e por isto diz Heidegger que o ser-no-mundo se abre, na disposição, como totalidade. A alegria, o bem-estar, o amor "contagiam" a totalidade que o mundo é para nós, mas também a tristeza, o mau-humor e o ódio "contaminam" a abertura de mundo como um todo. A disposição "é um modo existencial básico da co-originária abertura de mundo, ser-aícom e existência, porque esta abertura mesma é essencialmente ser-no-mundo" (Heidegger 1986, p. 137).

Dentre os três caracteres ontológicos essenciais da disposição - ontológicos porque por eles se abre o ser para o ser-aí -, o terceiro diz respeito mais diretamente à relação que pretendemos aqui explicitar, que é aquela entre o cuidado e o carecer. Este terceiro caráter ontológico consiste em que os entes só existem para o ser-aí em virtude das disposições, uma vez que estas tornam-no "abordável" pelos entes. O exemplo de Heidegger a respeito do temor é suficientemente expressivo do que significa esta "abordabilidade": somente a partir da disposição do temor pode um ente ameaçador aparecer para nós. O fato de que o tememos é que faz com que um ente apareça como ameaçador, pois é a disposição que comanda nossa atenção. Podemos, por outra, estar tão envolvidos numa conversação que nos esquecemos da hora, podemos estar tão absorvidos na leitura de um livro que nem sentimos fome, assim como frutas na fruteira podem ser percebidas por nós como possibilidade de matar a fome ou podem ser admiradas pela beleza da decoração que ajudam a compor, caso estejamos no estado de humor da contemplação estética. O teste de Rorschach, aplicado na psicologia clínica, ilustra bem este estado de disponibilidade da disposição - e o trocadilho, aqui, não é gratuito, absolutamente. Manchas, no mais das vezes simétricas, são mostradas a nós neste teste, e o que cada um vê ali, em manchas negras sobre um fundo branco, diferirá do que os outros em geral verão. Cada um vê, nestas figuras de contorno irregular, aquilo que sua disposição lhe permite ver: o que é flor para um será um morcego para outro, o que é uma mulher velha para um será uma árvore curvada para outro. Percebemos aquilo que nossas disposições nos permitem perceber. Citando Heidegger:

E apenas porque os 'sentidos' pertencem ontologicamente a um ente que tem o modo de ser do ser-no-mundo disposto, podem eles ser estimulados e 'ter sentido para', de tal modo que o estimulante mostra-se na afecção. Mesmo que tal coisa como afecção se dê pelas mais fortes pressão e resistência, a resistência permaneceria essencialmente não descoberta caso o ser-no-mundo disposto já não dependesse de uma, predefinida pelos humores, admissibilidade com o ente intramundano. [...] Um puro contemplar, mesmo que impelido às artérias mais interiores do ser de algo-simplesmente-dado, jamais poderia descobrir algo como ameaça. (Heidegger 1986, p. 137 e 138) 
Acreditamos que explica, até certo ponto, esta admissibilidade da disposição ao ente intramundano a afirmação do professor Ernst Tugendhat, no seu Selbstbewusstsein und Selbstbestimmung, de que Heidegger, em Ser e tempo, "defende a de fato esclarecedora tese de que ente não vem ao encontro isoladamente, mas sim em sua conformidade em meio a uma situação de ação determinada por interesses" (Tugendhat 1979, p. 186). ${ }^{1}$ Dizer que o ser-aí está interessado nisto ou naquilo explica, nos parece, por que razão os sentidos se fazem afetáveis por um determinado estimulante e não por outro, de modo que o ente intramundano se faça admissível pelo estado de humor - mas explica apenas parcialmente. Pois cabe, então, perguntar: e a partir de que se constituem os interesses? A resposta que nos ocorre é: os interesses se constituem a partir daquilo de que o ser-aí carece. Neste sentido, talvez não seja demasiado afirmar que a disposição tem por essência o carecer. Na carência o ser-aí se abre para o mundo, abre o mundo como lugar de onde pode vir aquilo de que se carece: o alimento, a bebida, a pessoa amada, o amigo, a paisagem, o dinheiro, a segurança, etc. Jogando um pouco com o absurdo, imaginemos que o ser-aí de nada necessitasse. Por que e de que modo (através de que) abrir-se-ia para o ente intramundano? Se este último só se apresenta como utensílio, ou seja, como algo que é para..., como algo que tem uma referência a outra coisa e por isto vem ao encontro sempre numa conformidade, e se totalidade conformativa remete necessariamente a um em virtude de, no caso de este último não ser determinado por uma necessidade (uma carência) do seraí, como, sob que condição apresentar-se-ia o ente intramundano? Se não for na condição de necessidade ou carência, como entender este em virtude de a partir do qual se constrói a totalidade conformativa? Mas, se pudermos entendê-lo assim, isto é, como necessidade ou carência, já que na disposição "reside existencialmente", como sua "determinação essencial", uma "abridora subordinação ao mundo", e posto que mundo, como totalidade conformativa, só se dá a partir de interesses (os quais só ocorreriam com base naquilo de que o ser-aí carece), conclui-se que indissoluvelmente ligado às disposições (aos humores) está o carecer.

Esta interpretação permite reforçar o que afirmamos anteriormente: que na disposição está a raiz, a base do ser próprio. Pois que seria o ser próprio de alguém, de um ser-aí qualquer em particular, se não for atenção às necessidades próprias e não anuência àquilo que se lhe diz que são suas necessidades? No impessoal o ser-aí decai de suas necessidades próprias para assumir conformada e alienadamente as que lhe são impostas.

Contudo, para que se veja suficientemente fundamentada esta ligação necessária que é aqui afirmada, entre as disposições e o carecer, é preciso que se apresente, em Ser e tempo, uma indicação clara da ligação entre a disposição e o em-virtudede. Mais adiante, depois de explicitar o papel reservado ao compreender interpretativo na abertura de mundo, voltaremos a esta questão.

\footnotetext{
Esta asserção de Tugendhat baseia-se, na verdade, nas próprias palavras de Heidegger. Dizendo que foi um ganho da pesquisa fenomenológica recuperar estes fenômenos, descritos por ele como disposição, para tema da Filosofia, lembra Heidegger que "Scheler, acolhendo estímulos sobretudo de Santo Agostinho e de Pascal, orientou a problemática relativamente às conexões de fundamentação entre os atos 'representativos' e os atos 'interessados'” (Heidegger 1986, 139).
} 


\section{III - O compreender interpretativo}

O compreender é o existencial, ou seja, a característica do ser do ser-aí, responsável pelo estabelecimento das totalidades conformativas. Portanto, se mais acima definimos mundo como totalidade das totalidades conformativas, então não haveria abertura de mundo sem esta capacidade de estabelecer referências, de estabelecer significâncias. Se podemos, como supomos aqui, identificar os emvirtude-de com carências, é lícito dizer que o compreender estabelece as relações de significância entre os manuseáveis de modo a atender à carência em que o emvirtude-de se constitui.

No entanto, é preciso ter claro que a construção de tais relações é, assim interpretamos aqui, algo que se aprende. Mundo é, de certo modo, prévio aos entes intramundanos. Afirma-o Heidegger, entre as páginas 68 e 69 do livro aqui tratado, nas quais diz ele que o quarto é aquilo que vem ao encontro mais imediatamente do que os diversos entes que nele estão ("utensílios de escrita, mesa, lâmpada, móveis, janela, portas, tinta, papel”) e que é a partir do quarto que se mostra a “'instalação' ('Einrichtung') e, nesta, cada respectivo utensílio 'singular'”. O quarto - usado ali como metáfora para mundo - só poderia vir ao encontro do ser-aí que somos porque se apresenta a nós, previamente aos entes que nele estão, como totalidade na qual estes entes como que "se inscrevem". Mas o quarto é o local onde dormimos ou nos vestimos ou trabalhamos - se não temos escritório. Portanto, o que o filósofo quer dizer é que o sentido que emprestamos às totalidades conformativas e não a mera justaposição de entes é que dá origem a estas totalidades. E no entanto - e isto queremos frisar aqui - tais totalidades são conformativas, o que significa que seja qual for o telos a que obedece seu vir-a-ser, são os entes que as formam, pois só os entes estabelecem conformidades entre si. Quando Heidegger diz que "antes (de cada utensílio singular) já é a cada vez descoberta uma totalidade utensiliar" (Heidegger 1986, p. 69), isto significa que cada utensílio só ganha sentido, isto é, só ganha sua utensiliaridade, em meio a tal totalidade; contudo, qualquer totalidade utensiliar (ou seja, conformativa) só se faz pelas diversas conformidades, pelas diversas significâncias que as relações de referência entre os manuseáveis constituem.

Como conseqüência de tudo isto, o que pretendemos, enfim, defender aqui é que estabelecer totalidades conformativas, ou seja, ser compreensivo é algo que se aprende; estas totalidades se constroem a partir das necessidades do ser-aí, isto é, se constroem com fundamento naquilo que Heidegger chama tecnicamente de em-virtude-de. Elas se põem entre este em-virtude-de e um objetivo que irá satisfazer a necessidade expressa no em-virtude-de. No exemplo mesmo de Heidegger à pág. 84, estabelece-se uma totalidade conformativa entre a necessidade de o ser-aí proteger-se contra as intempéries e a fixação do telhado. Cada utensílio singular ganha sentido pelas referências que tem com os outros utensílios: o martelo junto ao prego, o prego junto à tábua, a tábua junto à telha. Mas o aprendiz de carpinteiro teve eventualmente que aprender a estabelecer estas referências, a escolher o martelo adequado, o prego com o comprimento apropriado, a melhor 
madeira para se construir telhados, o tamanho da tábua, o tipo de telha, etc. Com a experiência, que só vem com o tempo de prática, o bom carpinteiro automatizará tais escolhas, que se farão em meio à totalidade utensiliar que se lhe apresentará zunächst e que dependerá do tipo de construção e de outras particularidades. Do mesmo modo, mundo se abre para nós todos como totalidade conformativa, ou melhor, como totalidades conformativas, dependendo de estarmos no trabalho, no clube, em casa, na rua e assim por diante. Abre-se como totalidade referencial com a qual procuraremos sempre, imediatamente, conjuminar qualquer ente simplesmente-dado que nos apareça como novidade, que surja como estranho à totalidade com a qual nos acostumamos. Porém, estas totalidades se constroem por meio do gradativo estabelecimento de referências, ou seja, por meio dos entes manuseáveis intramundanos, e com o tempo são automatizadas para constituir o mundo no qual vamos buscar a satisfação de nossas necessidades - ou, por outra, de nossas carências.

Este compreender, definidor dos para-que que são a essência mesma do utensílio manuseável, é, pois, projetivo. A partir dos em-virtude-de o ser-aí projeta totalidades conformativas que atenderão ao em-virtude-de como base da cadeia de significâncias. Não obstante, a partir de uma carência ou necessidade qualquer várias possibilidades de atendimento costumam apresentar-se. Num exemplo prosaico, posso ter vontade de comer pão francês e, então, diversas possibilidades projetadas se me apresentam como totalidades conformativas que se estabeleceriam entre a minha fome (ou gula) e a compra do pão: posso ir a pé até a padaria da esquina que é mais perto, mas onde o pão não é tão bom; posso andar um pouco mais até o supermercado onde o pão é mais barato, embora nada se ganhasse com isto em qualidade; ou posso pegar o carro ou a bicicleta e ir comprar o pão naquela padaria ótima do outro bairro, na qual o pãozinho é um pouco mais caro mas é muito mais gostoso. Diversas possibilidades são compreensivamente projetadas e é preciso escolher. Ao selecionar alguma, o compreender se faz interpretativo. A interpretação é, então, este existencial que seleciona dentre os vários projetos que se abrem, ou dentre os vários utensílios que se apresentam para a consecução do projeto, aquele que seria o mais apropriado. Escolher, no exemplo acima, entre o carro e a bicicleta, seria também um ato de interpretação.

\section{IV - A fala}

Mas naquela expressão complexa, citada logo de início, que pretende definir o cuidado como ser do ser-aí, a disposição é mencionada no já, o compreender no precedentemente a e mundo é citado diretamente. A fala, porém, é omitida. Ou talvez não, se entendermos que ela se expressa em cada hífen, pois segundo Heidegger a fala articula disposição e compreender. O modo segundo o qual ocorre esta articulação é um tanto vago em Ser e tempo, e como minha intenção aqui é ressaltar a relação entre o em-virtude-de, o carecer e a disposição, abordaremos apenas brevemente aquele existencial cujo termo designativo em alemão, Rede, tem sido traduzido para o português - no meu entender, equivocadamente - como discurso. 
Pretende Heidegger que a fala seja algo de distinto da linguagem, dado que "a fala é o fundamento existencial-ontológico da linguagem" (Heidegger 1986, p. 160). Cristina Lafont, em seu Sprache und Welterschliessung, critica este intento de Heidegger de diferenciar entre ambas e o credita ao fato de que, por ocasião de Ser e tempo, o filósofo estaria ainda muito preso aos pressupostos da filosofia de Husserl, a partir dos quais se fez necessário apresentar o ser-aí, no livro de Heidegger, como único ente ontológico (isto é, como o único ente por meio do qual ter-se-ia acesso ao ser). Não podendo admitir ainda, em Ser e tempo a linguagem como ontológica, cria Heidegger (segundo Lafont), a "abstração" da fala como caráter ontológico do ser-aí, com o que resguarda a exclusividade deste último.

Consideramos a argumentação de Lafont convincente, e cremos que a fala pode ser entendida, mantendo-se coerência com Ser e tempo, como sendo a linguagem simplesmente, embora não exclusivamente a linguagem verbal. A fala é a linguagem em que mergulhamos quando somos jogados numa facticidade, ela constitui o sercom que é essencial ao ser-aí e por meio dela aprendemos dos outros, já desde que nascemos, a estabelecer conformidades. O que estamos afirmando é que a utensiliaridade de cada ente em particular é aprendida por nós dos outros, através da fala e, por conseguinte, o significar, isto é, o estabelecimento de significâncias, constitutivo do projetar compreensivo, advém da fala. É ela, portanto, que possibilita estabelecer, a partir do em-virtude-de - o que quer dizer, da disposição - os projetos compreensivos que visam a satisfazer as carências que dão origem a estas disposições. Só podemos estabelecer tais projetos porque previamente aprendemos o que vai junto a que, tanto no que se refere ao estabelecimento de conformidades, quanto no que diz respeito à ligação das totalidades conformativas ao ser do ser-aí, ligação que não é propriamente uma conformidade, mas sim é o em-virtude-de. E é neste sentido que se deve entender a articulação exercida pela fala entre disposição e compreender: a linguagem, que a fala é, significa cada elo da cadeia de referências que se estabelece entre nossas carências e a satisfação das mesmas e assim articula nossas disposições ao compreender que lhes seja correspondente. Por isto todo compreender é disposto. Da ligação entre a fala e o compreender é muito expressivo o que vai dito à p. 87 de Ser e tempo:

O compreender (...) mantém as relações indicadas numa abertura prévia. No familiar manter-se-nisto, mantém-se este prévio como aquilo em que o referir-se do compreender se move. O compreender se deixa referir nestas e a partir destas relações mesmas. Nós apreendemos como signi-ficar o caráter relacional destas relações do referir-se. Na familiaridade com estas relações o ser-aí 'significa' para ele mesmo, ele originariamente se dá a compreender seu ser e poder-ser no tocante ao seu ser-no-mundo. O Em virtude de quê? significa um para-que, o para-que significa um para-isto, o para-isto significa um Junto a quê? do deixar-ser-conforme, este Junto a quê? do deixar-serconforme significa um Com quê? da conformidade. Estas relações são acopladas entre si mesmas como totalidade originária, elas são o que são, como este signi-ficar, nisto de que o ser-aí se dá a compreender previamente a si mesmo seu ser-no-mundo. O todo de referências deste significar, nós o chamamos de significância. Ela é o que constitui a estrutura do mundo, na qual o ser-aí, como tal, sempre já é. O ser-aí é, na sua familiaridade com a significância, a condição ôntica de possibilidade da descoberta 
de ente, o qual vem ao encontro num mundo no modo de ser da conformidade (manuseabilidade) e que pode, deste modo, manifestar-se no seu em-si. Ser-aí é, como tal, a cada vez este que, com seu ser, já é essencialmente descoberto um contexto de manuseáveis - uma vez que é, o ser-aí já sempre se referiu a um 'mundo' que vem ao encontro, pertence ao seu ser essencialmente esta condição de referido a. Porém, a significância mesma, com a qual o ser-aí já sempre está familiarizado, abriga em si a condição ontológica da possibilidade de que o ser-aí compreensivo, na qualidade de interpretativo, possa abrir algo como 'significações', as quais, por sua vez, fundamentam a possibilidade de ser de palavra e linguagem.

\section{V - As disposições, o em-virtude-de e o carecer}

Foi dito antes que se faz imprescindível apresentar a ligação entre a disposição e o em-virtude-de, caso se queira fundamentar suficientemente a interpretação que fazemos aqui. Entendemos que esta ligação é feita explicitamente por Heidegger no Parágrafo 41, quando ele lembra que na disposição se abre a facticidade do ser-aí (o seu que é e tem de ser). Ora, se ente intramundano só vem ao encontro do ser-aí em totalidades conformativas, que são, como vimos, necessariamente reconduzíveis ao em-virtude-de, e se tais totalidades só vem ao encontro numa determinada facticidade - aberta pela disposição - verifica-se, então, uma necessária ligação entre a disposição e o em-virtude-de, ao qual é reconduzível o ente em sua totalidade conformativa facticial. Dado isto, faz-se visível, então, uma ligação necessária entre as disposições e o carecer via em-virtude-de, uma vez que este último pode ser identificado com o carecer. É bom que se diga, não estamos afirmando uma identificação entre estados de humor e carências. O que se defende aqui, contudo, é uma relação genética entre ambos, como conseqüência da argumentação de Ser e tempo. As disposições seriam, possivelmente, expressão emocional das carências do ser-aí.

Neste ponto, cremos que se faz perceptível de que modo se entende aqui a tal co-originariedade entre os existenciais afirmada por Heidegger. Para que mundo se abra, é preciso que a partir das carências deste ente que somos estabeleçam-se totalidades conformativas nos projetos que o compreender interpretativo constitui. Estas carências geram respostas emocionais, isto é, disposições que determinam que projetos construir para atender às carências. Mas as significâncias estabelecemse somente em vista da fala, que deste modo coordena disposição e compreender, e é por isto que se diz em Ser e tempo que todo compreender é disposto e falante, assim como toda disposição é compreensiva e falante e toda fala é disposta e compreensiva. Por conseguinte, entendemos que os existenciais são co-originários da abertura no sentido de que são eles, em interação, que a originam, mas de modo algum seriam co-originários na abertura. Entendendo-se disposições como expressão emocional de nossas carências, e compreender e fala, respectivamente, como capacidade de estabelecer projetos e como linguagem que possibilita tais projetos uma vez que significa as relações entre os manuseáveis e as relações destes com o ser-aí, percebe-se que não se defende aqui nenhuma simultaneidade de origem entre os existenciais, senão que abre-se espaço para ilações não mencionadas em 
Ser e tempo, ${ }^{2}$ como a de que estabelecer projetos é algo que se aprende e a de que mundo, conseqüentemente, abre-se gradativamente a partir do estágio em que, ao nascer, somos pouco mais do que carências gritando por satisfação.

Calada naquela expressão complexa de que partimos - ser-já-precedentementea-si-em (o mundo) como-ser-junto-a (ente intramundano que vêm ao encontro) está a angústia, mas, em verdade, sem ela não é possível definir o ser-aí como cuidado. A angústia é considerada em Ser e tempo como disposição originária, pois segundo este livro o ser-aí é angustiado, ainda que não se aperceba disto. Esta disposição é, por assim dizer recalcada por meio da nossa imersão no impessoal, quando então vige nosso ser impróprio. Contudo, cabe a pergunta: se considerarmos a angústia como disposição que corresponde ao ser-para-a-morte (Sein zum Tode. Heidegger 1986, p. 235) como compreender projetivo, será possível definir o ser da criança como cuidado? Arriscamos, para terminar este texto, responder que não, pois não há para a criança a morte como possibilidade mais própria, irremissível, inexcedível, certa e indeterminada. Ser-aí é o ser humano que é angustiado pois é-para-a-morte, ele "sabe" da morte, embora no mais das vezes faça questão de fazer que não sabe. Mas é preciso ressaltar que tal pensar sobre a morte em Ser e tempo não têm nenhuma morbidez, pois, para Heidegger, a coragem de encarar, de assumir a certeza do nosso fim último é condição da recuperação do ser próprio de cada um e, por conseguinte, condição de vida como realização do que verdadeiramente queremos ser.

\section{Referências}

BOCK, Irmgard. Heideggers Sprachdenken. Meisenheim am Glan: Verlag Anton Hain, 1966.

FEICK, Hildegard. Index zu Heideggers “Sein und Zeit”. Tübingen: Max Niemeyer Verlag, 1968.

FIGAL, Günter. Phänomenologie der Freiheit. Frankfurt am Main: Verlag Anton Hain, 1991.

HEIDEGGER, Martin. Vom Wesen des Grundes. In Wegmarken. Frankfurt am Main: Vittorio Klostermann, 1967.

. Sein und Zeit. Tübingen: Max Niemeyer Verlag, 1986.

LAFONT, Cristina. Sprache und Welterschliessung. Frankfurt am Main: Suhrkamp Verlag, 1994.

NUNES, Benedito. Passagem para o poético. São Paulo: Ed. Ática, 1986.

ROSALES, Alberto. Transzendenz und Differenz. Köln: Dissertation, 1966.

TUGENDHAT, Ernst. Selbstbewusstsein und Selbstbestimmungen. Frankfurt am Main: Suhrkamp Taschenbuch Verlag, 1979.

2 E, é preciso que se reconheça, nem teriam por que ser mencionadas, já que o intento de Ser e tempo é outro que o de manter-se nos limites da antropologia. 